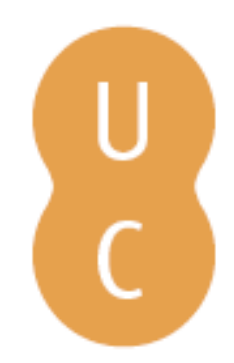

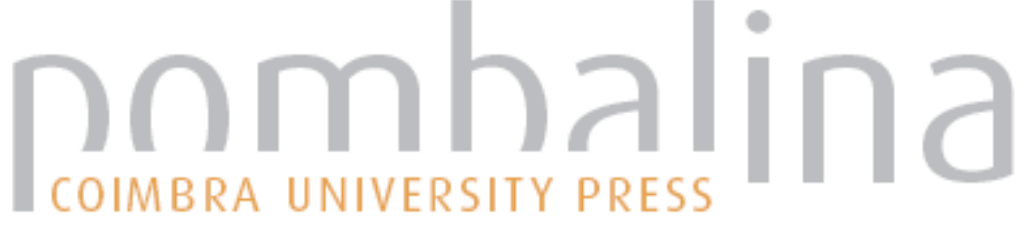

\section{Bibliotecas universitárias: regresso ao futuro 500 anos depois}

Autor(es): $\quad$ Figueiredo, António Dias de

Publicado por: Imprensa da Universidade de Coimbra

URL

persistente: URI:http://hdl.handle.net/10316.2/36976

DOI: $\quad$ DOI:http://dx.doi.org/10.14195/978-989-26-1045-0_5

Accessed : $\quad$ 26-Apr-2023 15:26:07

A navegação consulta e descarregamento dos títulos inseridos nas Bibliotecas Digitais UC Digitalis, UC Pombalina e UC Impactum, pressupõem a aceitação plena e sem reservas dos Termos e Condições de Uso destas Bibliotecas Digitais, disponíveis em https://digitalis.uc.pt/pt-pt/termos.

Conforme exposto nos referidos Termos e Condições de Uso, o descarregamento de títulos de acesso restrito requer uma licença válida de autorização devendo o utilizador aceder ao(s) documento(s) a partir de um endereço de IP da instituição detentora da supramencionada licença.

Ao utilizador é apenas permitido o descarregamento para uso pessoal, pelo que o emprego do(s) título(s) descarregado(s) para outro fim, designadamente comercial, carece de autorização do respetivo autor ou editor da obra.

Na medida em que todas as obras da UC Digitalis se encontram protegidas pelo Código do Direito de Autor e Direitos Conexos e demais legislação aplicável, toda a cópia, parcial ou total, deste documento, nos casos em que é legalmente admitida, deverá conter ou fazer-se acompanhar por este aviso. 

Tendo como pano de fundo as Comemorações dos seus 500 anos, a Biblioteca Geral da Universidade de Coimbra organizou um Congresso Internacional subordinado ao tema "A Biblioteca da Universidade: permanência e metamorfoses", que teve lugar nos dias 16, 17 e 18 de janeiro de 2014, no auditório da Reitoria da Universidade de Coimbra.

O objetivo maior desta reunião científica foi o de refletir sobre o presente e o futuro das bibliotecas que servem públicos universitários. Numa outra vertente, procurou chamar-se a atenção para a importância de que a Biblioteca se reveste, tendo em vista o progresso do conhecimento técnico e científico. Por último, o Congresso pretendeu instituir-se como oportunidade de reflexão prospetiva e como lugar de encontro entre as sensibilidades de todos os que trabalham profissionalmente com livros e com outros suportes de natureza bibliográfica.

Nesse sentido, foram apresentadas Conferências, Mesas Redondas e sessões de Testemunhos em torno de temas como o valor das bibliotecas universitárias, a biblioteca universitária em contexto; as mudanças e os desafios; a biblioteca universitária e a sociedade da informação e conhecimento; o impacto do acesso aberto na comunidade científica, e as bibliotecas digitais. 


\section{ANTÓNIO DIAS DE FIGUEIREDO}

Universidade de Coimbra

University of Coimbra

B I B L I O T E CAS U NIVERS ITÁRIAS:

REgRESSO AO FUTURO 500 ANOS DEPOIS

UNIVERSITY LIBRARIES: BACK TO THE FUTURE 500 YEARS ON

RESUMO: As interrogações que hoje se acumulam sobre o futuro das bibliotecas universitárias, num mundo transformado por novas literacias, novas formas de relacionamento social, novos recursos e suportes, novos desafios culturais e novas visões sobre o que deve ser a universidade dos nossos dias, justificam que procuremos compreender a missão que as bibliotecas universitárias terão a desempenhar no seio dessas transformações. Ao fazê-lo, podemos avançar conjeturas sobre futuros que se adivinham ou, pelo contrário, escrutinar o passado em busca de padrões intemporais de convivência entre saberes acumulados (bibliotecas), saberes em construção (investigação científica) e saberes difundidos e partilhados (universidades, na sua função pedagógica). Neste texto, procuro conciliar os percursos do passado com os do futuro, numa síntese que aborde os principais dilemas que hoje cruzam o debate do futuro destes três tipos de entidades: universidades, investigação e bibliotecas.

ABSTRACT: The mounting number of questions concerning the future of university libraries in a world transformed by new forms of literacy and social relations, new resources and supports, new cultural challenges and new visions of what a modern university should be, justify the need to understand the role which university libraries will have to play at the heart of these changes. In doing so, we may speculate on possible future scenarios or, conversely, examine the past in search of timeless patterns for the coexistence of forms of knowledge already accumulated (libraries), knowledge in construction (scientific research) and knowledge disseminated and shared (universities as teaching institutions). This paper aims to reconcile the approaches adopted in the past with those of the future, in a synthesis which addresses the main dilemmas nowadays entwined in the debate on the future of these three entities: universities, research and libraries. 


\section{Dilemas da Universidade}

Os dilemas com que as universidades hoje se debatem são de larga monta e ameaçam mesmo o modelo de universidade que hoje conhecemos. Em Portugal, os dilemas são semelhantes aos que se vivem em todo o mundo, mas as fragilidades que se encontram no nosso país são largamente superiores. Partindo de muitos anos de reflexão sobre as questões da estratégia e qualidade no ensino superior, a nível global, e de cerca de quinze anos de reflexão sobre o caso português, no âmbito do meu envolvimento nos processos de avaliação e acreditação do Conselho de Reitores das Universidades Portuguesas, da Ordem dos Engenheiros e, mais recentemente, da Agência de Avaliação e Acreditação do Ensino Superior (A3ES), procurarei abordar aqui alguns desses dilemas. Antes de mais, observa-se na maioria das nossas instituições uma imensa ausência de sentido estratégico. Essa ausência é por sua vez agravada (e em parte explicada) por uma notória carência de lideranças. Sofrendo dessas carências, muitas das universidades portuguesas tendem a tornar-se quase iguais entre si, sem aparentemente se preocuparem em diferenciar a sua oferta. Os seus hábitos de autocrítica são, por outro lado, praticamente inexistentes, impedindo a emergência de culturas de mudança. A elevada inércia dos seus princípios e práticas conduz a evoluções lentas e conservadoras, que excluem a emergência de inovações disruptivas. Finalmente, muitas das universidades portuguesas tem dificuldade em conceber-se projetada para o país e para o mundo, resignando-se com uma implantação local ou regional sem ambição. No contexto destes dilemas das universidades portuguesas, que a seguir tentarei caracterizar melhor, procurarei posteriormente conjeturar sobre potenciais intervenções das bibliotecas universitárias no sentido de contribuírem para a sua superação.

\subsection{Estratégia versus tática}

De entre as práticas que caracterizam as organizações dos nossos dias, a estratégia é talvez a mais ausente da história da universidade. Nascida 
dos poderes real e eclesiástico, a universidade não necessitava, desde a sua origem, de se sonhar e projetar para o futuro. Necessitava, sim, de se manter fiel aos desígnios do poder que a tutelava. Compreende-se por isso que quando, na segunda década do século $\mathrm{XX}$, as empresas começaram a reconhecer a importância da estratégia, o valor da gestão moderna, o primado do cliente, a intensificação da concorrência e a incerteza da realidade socioeconómica ${ }^{1}$, a universidade se tivesse mantido relativamente indiferente.

A universidade, que tinha atingido no início desse período o auge da sua popularidade, começava, entretanto, a ser criticada pela sua incapacidade para acompanhar o seu próprio sucesso. Os estudantes queixavam-se das salas superlotadas, das relações impessoais com os docentes, dos métodos de ensino massificados, do exagero da teoria relativamente à prática, do arbítrio das avaliações, da falta de coerência dos planos de estudo e do desajuste entre a formação universitária e a realidade do mercado de trabalho. Os recrutadores queixavam-se da deficiente preparação dos recém-licenciados para as realidades da prática, da sua pobreza de atitudes e valores para o exercício da profissão e da indiferença dos planos de estudos relativamente à necessidades do mercado. Por seu lado, os governos e os contribuintes, que pagavam a fatura, queriam saber como é que os dinheiros eram gastos e reclamavam contra o amadorismo da gestão universitária ${ }^{2}$.

O agudizar dessas tensões, associado à onda de neoliberalismo que entretanto varreu os sistemas de ensino superior ocidentais, conduziu à universidade que hoje conhecemos, subfinanciada e governada por gestores que marginalizam a função académica ${ }^{3}$. A tragédia desta transformação reside em que os académicos - que nas últimas décadas do século $\mathrm{XX}$

\footnotetext{
1 Hammer, Michael, CHAMPY - Reengineering the Corporation: A Manifesto for Business Revolution. New York: Harper Collins, 1993.

2 Figueiredo, António Dias - Reinventar Portugal: Universidade. Diário Económico. Lisboa: DE, 1996. 12 Julho 1996.

3 Ginsberg, Benjamin - The Fall of the Faculty: The Rise of the All-Administrative University and Why It Matters. New York: Oxford University Press, 2011.
} 
podiam ter acompanhado os progressos da gestão moderna ${ }^{4}$, adaptando-a à singularidade da instituição universitária e reconhecendo o emergente primado do utente e da concorrência - acabaram, pelo amadorismo da sua governação, por ser substituídos por gestores empresariais que transformaram a universidade no travesti de empresa que hoje conhecemos. Como a tradição de pensar estrategicamente a universidade era reduzida, e os novos gestores tendem a encará-la como uma mera empresa, numa lógica simplificada de ganhos e perdas, a universidade centra-se hoje quase unicamente no curto prazo. Vivemos assim o absurdo de, num mundo onde a estratégia face à incerteza e à concorrência assume importância vital, a generalidade das universidades se contentar em construir o futuro de improviso, navegando à vista, projetando-se de um ano académico para o seguinte e criando cursos e planos de estudo muitas vezes incapazes de anteciparem o mercado de trabalho que os graduados irão encontrar.

Um dos desafios que a universidade tem de resolver é este, de conciliar o estratégico com o tático, o longo prazo com o curto prazo. Familiarizada que está com o curto prazo, cabe-lhe agora esforçar-se por se projetar para o futuro. Dizia Séneca que "não há vento que ajude quem não sabe para onde quer ir". Perdida como anda, embarcação sem rumo em mar agitado, que poderá fazer a universidade perante as oportunidades e ameaças que lhe forem surgindo, se não souber para onde quer ir? Que visão ou visões procura cada universidade sonhar para o seu futuro? Conseguirá, sem uma projeção para esse futuro, mobilizar a sua complexa teia de partes interessadas? Não será verdade, como diz o antigo ditado castelhano, que "quem não constrói castelos no ar não os constrói em nenhum lugar"?

${ }^{4} \mathrm{O}$ conceito de "gestão moderna", que optei por usar aqui, diz respeito à revolução a que se assistiu nas ciências da organização a partir da segunda metade do século XX, que trouxe consigo métodos inteiramente novos para encarar a gestão das organizações métodos centrados nas pessoas e muito mais estratégicos, eficazes, eficientes. $\mathrm{O}$ autor mais representativo desse vasto movimento foi, talvez, Peter Drucker, que lhe dedicou toda a sua vida, começando em 1954 com a publicação de "The Practice of Management". Infelizmente, grande parte das universidades de todo o mundo manteve-se indiferente ao movimento, passando diretamente dos processos artesanais de gestão que tinha mantido ao longo dos séculos para as práticas de gestão neoliberal, onde a gestão moderna é desastrosamente deturpada em benefício da gestão de lucros e perdas. 


\subsection{Liderança versus gestão}

Não se tendo apercebido, ou tendo-se apercebido tardiamente, da importância da gestão moderna, que interiorizou contra natura, a universidade tende agora a concentrar-se de forma obcecada no que pensa ser a "gestão" dos seus procedimentos. Desdobra-se, assim, em burocracias, numa empresarialização arremedada que complica, atrasa e desumaniza os processos, afronta o espírito académico e divide as pessoas.

Neste percurso de deterioração, a universidade fecha-se à emergência de lideranças, entendidas no sentido moderno, que exclui lideranças ditatoriais e incentiva, sim, em seu lugar, processos coletivos capazes de imprimir direção, apaixonar e mobilizar todas as partes, construindo mudança e instilando uma cultura e uma ética. O desafio que se coloca à universidade é o de fomentar a emergência dessas lideranças em perfeita ligação com os seus processos de gestão. Em boa verdade, uma gestão genuína, à luz dos padrões dos nossos dias, contém em si própria as lideranças que a asseguram e humanizam de forma sustentada. Mais ainda, as lideranças dos nossos dias não se restringem às instituições que representam, prolongando-se indefinidamente nas interações entre essas instituições e as outras instituições que povoam o respetivo ecossistema.

\subsection{Diferenciação versus uniformização}

Na ausência de uma visão estratégica para o seu futuro, muitas universidades satisfazem-se em "fazer como as outras", sem aparentemente se interessarem em reforçar os que as torna diferentes e em construir sobre essa diferença a sua imagem de marca. Pelo contrário, parecem sentir-se mais seguras irmanadas na uniformidade. É raro observar uma universidade que procure analisar estrategicamente as suas competências-chave, contextuais e internas, e que procure estabelecer, a partir dessa análise, uma carteira de competências que, diferenciando-a das demais, lhe permita projetar-se para o país e para o estrangeiro. Na novela "O Homem Sem Qualidades", Robert Musil, um escritor austríaco do início 
do século passado, conta as histórias de Ulrich, um indivíduo que procura encontrar um sentido para a sua vida e que descobre que, como não tem qualidades, todas as oportunidades que se lhe abram são indiferentes. A semelhança entre estas universidades e Ulrich é, por vezes, perturbadora. Por outro lado, não se sentindo com qualidades, estas universidades parecem incapazes de construir e promover uma imagem de marca que as apresente perante o exterior e lhes permita, em simultâneo, consolidar e dar coerência à sua estratégia.

Para que as universidades se libertem desta limitação à sua capacidade de afirmação, torna-se indispensável que conciliem os benefícios de alguma uniformidade com o elevado potencial de uma estratégia de diferenciação.

\subsection{Desconstrução versus construção}

A desconstrução é um conceito da análise literária ${ }^{5}$, hoje alargado à linguagem corrente, que o entende como prática social e intelectual. Desconstruir é pôr em causa as ideias instaladas, e assim decidir se ainda são válidas ou se devem ser renovadas. A desconstrução contém o embrião do futuro, na medida em que, na ausência de reflexão crítica sobre as ideias dominantes, o futuro será igual ao passado.

Como a universidade tende a encarar com desconforto a sua autocrítica, tem dificuldade em pensar-se como instituição do futuro. Por isso se constrói incrementalmente, melhoramento a melhoramento, sem analisar criticamente as suas realizações passadas nem os valores dos quais elas emanaram. Uma universidade que queira pensar-se estrategicamente terá de saber constituir uma cultura e uma orgânica institucional que lhe permitam interrogar-se criticamente sobre os seus modelos e práticas. Poderá, então, conciliar harmoniosamente os extremos entre a desconstrução e a indispensável construção.

5 DERridA, Jacques - Of Grammatology. Baltimore: The Johns Hopkins University Press, 1997. 


\subsection{Disrupção versus evolução}

É frequente distinguir dois tipos de inovação: a inovação incremental e a inovação disruptiva. A primeira corresponde à evolução, a segunda à rutura. Uma inovação é incremental quando se limita a introduzir melhoramentos graduais nas soluções já existentes. São exemplos de inovação incremental as televisões com imagens 3D, os aviões com maior autonomia ou as baterias com maior duração. Uma inovação é disruptiva quando cresce discretamente à margem dos sistemas sociais tradicionais, das margens para o centro, e se afirma pela conquista gradual de utentes que toleram as suas imperfeições iniciais e contribuem para que sejam superadas $^{6}$. O computador pessoal, que nasceu como brinquedo para as crianças e famílias, e que em cerca de vinte anos evoluiu ao ponto de eliminar dos mercados os computadores profissionais, é exemplo de uma inovação disruptiva. Outro exemplo é a Internet, que nasceu como rede experimental para cientistas, com frequentes falhas e anomalias, e se transformou em poucos anos na mais poderosa rede de redes do mundo.

Embora as universidades sejam por natureza instituições inovadoras, as suas inovações são por tradição exclusivamente evolutivas. Ora, como aponta Christensen ${ }^{7}$, num mundo em rápida transformação, onde as oportunidades e ameaças tecnológicas e de mercado aumentam a olhos vistos, as maiores oportunidades de diferenciação e sucesso para uma universidade encontram-se na inovação disruptiva. O debate sobre esta temática tem vindo a intensificar-se nos mais diversos meios, apontando para mudanças iminentes na natureza da universidade 8 . O desafio com que se confronta a universidade, a este nível, é, assim, o de conciliar a solidez das suas práticas de inovação incremental com o potencial das inovações disruptivas que pode hoje pôr em prática, ao nível das peda-

6 Christensen, Clayton M. - The Innovator's Dilemma: When New Technologies Cause Great Firms to Fail. Boston, Mass: Harvard Business School Press, 1997.

7 CHRISTEnsen, Clayton M. - The Innovative University: Changing the DNA of Higher Education from the Inside Out. San Francisco: Jossey-Bass, 2011.

8 Economist - Creative Destruction. The Economist (28 Jun 2014). [Acedido a 20 de Jul. de 2014]. Disponível na WWW em: <URL:http://www.economist.com/news/leaders/21605906cost-crisis-changing-labour-markets-and-new-technology-will-turn-old-institution-its $>$. 
gogias, do recurso às tecnologias, da afirmação da sua imagem e dos seus próprios modelos de negócio.

\subsection{Globalização versus localização}

Por falta de estratégia e liderança, muitas universidades aceitam hoje docilmente o seu estatuto local ou regional. Como os alunos que as frequentam provêm maioritariamente da sua região, ou mesmo da sua cidade, as universidades aceitam tal limitação como uma fatalidade: restringem as medidas de atração e esclarecimento dos potenciais alunos de licenciatura a iniciativas tímidas dirigidas às escolas secundárias locais, publicitam os seus mestrados quase exclusivamente junto dos próprios alunos de licenciatura, e angariam os estudantes de doutoramento no universo restrito dos seus departamentos ou escolas próximas. O contraste entre esta ausência de ambição e o conceito tradicional de universidade não podia ser maior. Como acentuava Braga da $\mathrm{Cruz}^{9}$, o que, desde o século XII, distinguia as universidades das escolas que as precediam era o seu caráter universal, a sua abertura para o mundo.

Curiosamente, várias das universidades portuguesas, quer do litoral, quer do interior, estão inseridas em meios e possuem atributos que lhes permitiriam diferenciar a sua oferta e abri-la ao país. Em alguns casos, podiam mesmo alargá-la para o estrangeiro, em particular no capítulo dos doutoramentos, para os quais a oferta nacional, mesmo depois do aumento das propinas para estudantes estrangeiros, se mantém competitiva a nível global. A este nível, o desafio que se coloca às universidades é o de explorar em toda a sua extensão estratégica a conciliação entre afirmação regional e projeção para o país e para o mundo.

9 Braga DA CruZ, Guilherme - Origem e Evolução da Universidade. In Obras Esparsas, vol. IV, 2. ${ }^{a}$ parte. Coimbra: Universidade, 1985, p. 189-262. 


\section{Dilemas da Construção dos Saberes}

A evolução tecnológica das últimas décadas tem vindo a provocar nas culturas, orgânicas e práticas da construção de conhecimento profundas alterações que, pela sua variedade e extensão, seria impossível abordar aqui. Restrinjo-me, por isso, às três que se afiguram mais relevantes no contexto de uma reflexão sobre a missão das bibliotecas universitárias. Antes de mais, o surgimento e consolidação de um novo modelo social de produção e aplicação do conhecimento, que Gibbons et al. ${ }^{10}$ designaram por modelo de "modo 2", em contraste com o modelo tradicional, que designaram por modelo de "modo 1". Outra alteração é o aumento da popularidade das novas alternativas para a avaliação da qualidade e impacto da produção científica, e o concomitante aumento da contestação às abordagens tradicionais, dominadas pelas grandes editoras da publicação científica. A terceira alteração diz respeito à popularidade crescente das práticas de acesso aberto, que nos últimos anos tem vindo a recolher grande apoio das universidades, com a indispensável intervenção das suas bibliotecas.

\subsection{Modo 1 versus Modo 2}

Até há algumas décadas, o conhecimento gerador de inovação originava em larga medida nas universidades e era transposto para a realidade social e económica por processos de transferência de conhecimento ${ }^{11}$. Nesse modelo social de produção de conhecimento, designado por Gibbons et al. ${ }^{12}$ como de "modo 1 ", as agendas de investigação são definidas pelos interesses académicos e desenvolvidas em ambientes predominantemente

10 GibBons, Michael [et al.] - The New Production of Knowledge. London: SAGE Publications, 1994.

11 FigueIREdo, António Dias - Formar para as Humanidades nas Sociedades Contextuais, in SILVA, A. S. [et al.] (eds.) - Novos Horizontes para as Humanidades. Braga: Universidade Católica Portuguesa, 2006, pp. 25-45.

12 Gibbons, Michael [et al.] - The New Production of Knowledge. 
universitários, no âmbito de grupos disciplinares relativamente homogéneos. Os seus principais destinatários são as audiências de pares, sendo os mecanismos de controlo da qualidade igualmente assegurados pelos pares. Uma vez produzido pelos académicos, esse conhecimento é então tornado acessível a profissionais que desenvolvem as eventuais aplicações. A ponte entre teoria e prática não é, assim, em princípio, construída pelos próprios cientistas, mas sim por profissionais da aplicação e da execução cuja contribuição para o reforço de tal conhecimento é normalmente tida por pouco relevante do ponto de vista científico. Os critérios de controlo de qualidade do modo 1 tendem a refletir os interesses e preocupações de uma comunidade científica disciplinar e dos seus defensores, que determinam implicitamente quem deve ser julgado como par, quais as questões que interessa ou não investigar e que métodos de investigação devem ser usados.

Nas últimas décadas, como observam ainda Gibbons e coautores ${ }^{13}$, começou a tonar-se dominante um modelo alternativo de construção de conhecimento, o modelo de "modo 2". O modo 2 centra-se explicitamente na produção de conhecimento e soluções destinadas a criar valor socioeconómico. As respetivas agendas de investigação nascem da partilha de interesses entre variadas partes interessadas - universidades, empresas e governos - e a investigação desenvolve-se nos múltiplos locais de trabalho dessas partes, gerando fluxos permanentes entre uns e outros, entre o que é fundamental e o que é aplicado e entre o que é teórico e prático. A investigação é tipicamente produzida por equipas mistas, de cientistas, profissionais da aplicação e outros, é eminentemente transdisciplinar e é heterogénea nas competências e experiências que mobiliza. De um modo geral, o conhecimento é construído nos contextos onde é usado, e os seus produtos e resultados, à medida que vão sendo obtidos, contribuem para novos desenvolvimentos e avanços teóricos ${ }^{14}$. A procura de saberes é mais orientada para a obtenção de resultados do que para a descoberta de teorias e princípios, o conhecimento tácito dos diversos parceiros é

\footnotetext{
13 Gibbons, Michael [et al.] - The New Production of Knowledge.

14 FigueIREdo, António Dias - Formar para as Humanidades nas Sociedades Contextuais.
} 
muitas vezes mais importante do que o explícito, e as iniciativas têm lugar no âmbito de "projetos", segundo uma tradição muito mais típica dos contextos industriais do que da investigação científica tradicional.

Embora os critérios de controlo de qualidade do modo 1, como a revisão pelos pares, também se apliquem no modo 2 , passam a combinar-se com critérios adicionais. Este conjunto mais complexo e multidimensional de critérios reflete-se na composição do sistema de avaliação dos projectos, que deixa de se restringir à apreciação da excelência científica pelos pares disciplinares para considerar agora, muitas vezes de forma predominante, a relevância económica e social dos resultados e a satisfação das expectativas e interesses das diversas partes ${ }^{15}$.

Refletindo sobre esta realidade à luz da missão renovada das bibliotecas universitárias, apercebemo-nos de que, mesmo que as universidades mantenham grande parte da sua produção científica em modo 1, como ainda acontece predominantemente em Portugal, a tendência de migração para o modo 2 - imposta cada vez mais pelos modelos de financiamento da investigação e pela necessidades de abertura das universidades à colaboração com múltiplos parceiros - obrigará as bibliotecas universitárias a assumirem um papel cada vez mais ativo ao serviço do novo paradigma.

\subsection{Métricas alternativas versus métricas tradicionais}

Outro aspeto importante do controlo da qualidade da produção científica surge em ligação com as métricas usadas para avaliar essa produção. Tradicionalmente, e ainda hoje, predominam as métricas de impacto estabelecidas pelas grandes editoras - Thomson Reuters (Web of Science) e Elsevier (Scopus). No entanto, a contestação a estes modelos tem vindo a aumentar de tom nos últimos tempos, cada vez com maior apoio por parte de universidades e associações científicas, dando lugar à emergência de métricas alternativas, ou Altmetrics, baseadas em outros índices de qualidade e reputação. Alguns exemplos são os sistemas PlumX (da Plum

\footnotetext{
15 Figueiredo, António Dias - Formar para as Humanidades nas Sociedades Contextuais.
} 
Analytics, recentemente adquirida pela EBSCO), Impact Story (financiada pela Alfred P. Sloan Foundation, National Science Foundation e outros patrocinadores) e Altmetric (uma empresa do Reino Unido), que recolhem as suas informações de reputação científica a partir de múltiplas fontes, e não apenas a partir das tradicionais.

Reconhecendo a nova problemática como do âmago das suas funções, visto que implica estratégicas e práticas inteiramente novas no apoio aos seus utentes, as bibliotecas das universidades mais destacadas têm vindo a debruçar-se atentamente sobre estas questões ${ }^{16}$.

\subsection{Acesso aberto versus publicações tradicionais}

Intimamente ligado às questões da produção do conhecimento científico, surge o acesso a esse conhecimento, tradicionalmente dominado pelas grandes editoras e protegido por elevadas barreiras de custos, cada vez mais insustentáveis para as bibliotecas universitárias e instituições de investigação. Com a Internet a tornar tecnicamente possível o acesso on-line à produção científica global, sem custos de impressão nem de transportes, começaram a surgir múltiplas iniciativas no sentido de assegurar a abertura plena desse acesso, em particular para os resultados dos projetos financiados por dinheiros públicos.

Foi assim que começou a ganhar forma o movimento de acesso aberto, que a "Budapest Open Access Initiative", lançada em Dezembro de 2001, contribuiu para consolidar ${ }^{17}$. De acordo com esta iniciativa:

“Por 'acesso aberto' [à literatura científica com revisão por pares], queremos dizer a sua disponibilidade livre na Internet, permitindo a qualquer utilizador ler, fazer download, copiar, distribuir, imprimir, pesquisar ou referenciar o texto integral desses artigos, recolhê-los para indexação, introduzi-los como

16 King, P., ThunA, M. - Altmetrics in Context. Ottawa, Ontario: Canadian Association of Research Libraries, 2013.

17 BoAI - Budapest Open Access Initiative. [Em linha]. [S.1.]: BOAI, 2002. [Consult. a 20 de Jul. de 2014]. Disponível na WWW em: <URL:http://www.budapestopenaccessinitiative.org/>. 
dados em software, ou usá-los para outro qualquer fim legal, sem barreiras financeiras, legais ou técnicas que não sejam inseparáveis do próprio acesso à Internet. As únicas restrições de reprodução ou distribuição, e o único papel para o copyright neste domínio, deveria ser dar aos autores controlo sobre a integridade do seu trabalho e direito de ser devidamente reconhecido e citado"18.

O acesso aberto ocupa hoje lugar de destaque nas políticas de um número crescente de universidades, que têm vindo a adotar mandatos de acesso livre ${ }^{19}$ Um mandato de acesso livre é um conjunto coerente de políticas assumidas por uma universidade ou unidade de investigação no sentido de incentivar os seus investigadores a disponibilizarem em acesso aberto todos os trabalhos e publicações que produzirem para revisão pelos pares, quer auto-arquivando as respetivas versões finais no repositório da instituição ou num repositório disciplinar ("acesso aberto verde"), quer publicando-os em revistas de acesso aberto ("acesso aberto dourado"), quer fazendo as duas coisas. A identificação de boas práticas para as políticas de acesso aberto das universidades é hoje um tema amplamente debatido e caraterizado ${ }^{20}$.

\section{Dilemas das Bibliotecas}

Abordando agora os dilemas que se colocam às bibliotecas, independentemente da sua ligação às universidades e à construção de saberes, procurarei abordar a mutação surgida nas políticas de aquisição, a

18 BoAI - A Iniciativa de Acesso Aberto de Budapeste, 10 Anos Depois [Em linha]. [S.L.]: BOAI, 2012 [Consult. a 20 de Jul. de 2014]. Disponível na WWW em: <URL:http://www. budapestopenaccessinitiative.org/boai-10-translations/portuguese>.

19 ROARMAP - ROARMAP: Registry of Open Access Repositories Mandatory Archiving Policies [Em linha]. [Consult. a 20 de Jul. de 2014]. Disponível na WWW em: <URL:http:// roarmap.eprints.org/>.

20 Shieber, S, Suber, P. - Good Practices For University Open-Access Policies [Em linha]. Harvard: Harvard University, 2013 [Consult. a 20 de Jul. de 2014]. Disponível na WWW em: <URL:http://cyber.law.harvard.edu/hoap/sites/hoap/images/Bestpracticesguide-2013.pdf>. 
multiplicidade de estratégias que a Internet abriu para a pesquisa de informação, o desejado estímulo à descoberta acidental num mundo de convergência, a imprevista subida da importância dos contextos relativamente aos conteúdos, as problemáticas da gestão dos espaços, o incentivo à criação de comunidades, e a renovada complementaridade entre a missão das bibliotecas e as expectativas dos utentes quanto ao papel dos bibliotecários.

\subsection{Just-in-time versus just-in-case}

A tradição das bibliotecas universitárias, e em particular das bibliotecas departamentais, no culminar da era das disciplinaridades, era adquirir todas as obras relevantes e assinar todas as revistas representativas das respetivas disciplinas. Mesmo que não fossem de interesse imediato e se mantivessem ignoradas durante anos, eram cuidadosamente encadernadas e preservadas, para que estivessem disponíveis quando fossem necessárias ao trabalho de um investigador ou para que a sua descoberta, por feliz e inesperado acaso, pudesse, por vezes, alterar o curso da história. O acervo valioso, e muitas vezes único, de uma biblioteca universitária era um elemento chave da imagem de marca de uma universidade, à qual ocorriam com frequências cientistas exteriores, que aí se deslocavam para o consultar. A política que então sustentava as aquisições da biblioteca era uma política de "just-in-case", ou de acumulação preventiva - adquiria-se uma obra, não porque fosse necessária no imediato, mas porque um dia podia vir a ser necessária. Hoje, com a explosão dos saberes e das interdisciplinaridades, o aumento dos custos das publicações e a possibilidade de obter acesso on-line à grande maioria das obras e revistas científicas, a política do "just-in-case” deu lugar à política do "just-in-time" 21 - pesquisam-se instantaneamente e adquirem-se on-line os

21 Figueiredo, António Dias - Balanço Final do Encontro, Nova Universidade, Nova Informação: Bibliotecas em Rede [Em linha]. Lisboa: Laboratório Nacional de Engenharia Civil, 1995. [Consult. a 20 de Jul. de 2014]. Disponível na WWW em: <URL:http://eden.dei. uc.pt/ adf/bibrede.htm>. 
artigos de todas as revistas, sempre que necessário, e adquire-se também on-line, nova ou em segunda mão, em edição original, fac-similada ou eletrónica, virtualmente qualquer publicação. A política de acumulação preventiva deu lugar a uma política de acesso em contexto ${ }^{22}$.

\subsection{Estratégias múltiplas versus palavras-chave}

As técnicas de pesquisa alteraram-se também de forma radical. Tradicionalmente, recorria-se quase exclusivamente à pesquisa por palavras-chave, enriquecida com operadores booleanos. Hoje, ainda que as formas de pesquisa tradicionais se mantenham, o seu papel tem vindo a tornar-se residual quando comparado com o da grande variedade de outras estratégias e práticas, incluindo pesquisas associativas e semânticas, modalidades variadas de curadoria, folksonomias, múltiplas explorações de thesaurus e mapas conceptuais dinâmicos, para além do recurso a redes sociais especificamente para efeitos de pesquisa e à interação direta com autores e peritos.

\subsection{Divergência versus convergência}

As formas tradicionais de pesquisa são eminentemente convergentes, permitindo-nos encontrar cada vez mais sobre cada vez menos. No entanto, como apontava Umberto Eco, o excesso de convergência é nocivo porque exclui a riqueza das descobertas acidentais, tão importantes para incentivar a criatividade. Para ele, toda a ideia de biblioteca se baseia no mal-entendido de que o leitor vai à biblioteca para encontrar um livro cujo título conhece. Pelo contrário, segundo Eco, o essencial da função da biblioteca é que o leitor descubra livros cuja existência desconhecia

22 Figueiredo, António Dias - A Língua Portuguesa e o Desafio das Novas Tecnologias: Iliteracias e Contextos. In A Língua Portuguesa: Presente e Futuro. Lisboa: Fundação Calouste Gulbenkian, 2004. 
e que se tornam de primeira importância para ele 23 . A capacidade para "encontrar o que não se procura procurando o que não se encontra" 24 , ou serendipidade, tem, de facto, um papel decisivo nos processos de inovação, sendo hoje particularmente desejada no acesso a bibliotecas digitais $^{25}$.

\subsection{Contextos versus conteúdos}

Quase sem que se desse por isso, embora tenha acontecido num período de tempo relativamente curto, a Internet retirou grande parte da importância às bibliotecas como repositórios de conteúdos. As bibliotecas universitárias tendem a ser hoje responsáveis pelos repositórios digitais das suas instituições, nomeadamente no âmbito do imparável movimento de acesso aberto, e nesse sentido constituem-se como nós importantes da Internet dos conteúdos. No entanto, a sua função de prestadoras diretas do acesso a esses conteúdos tende a desaparecer. Por isso, várias bibliotecas têm vindo a deslocar a sua função do domínio do acesso aos conteúdos para o domínio da criação de contextos ou ambientes enriquecidos, que as transformam em espaços de aprendizagem, socialização e colaboração. Em particular, começam a ser frequentes as bibliotecas que constituem centros de aprendizagem (locais e globais), centros de cultura (locais e globais) e centros de iniciativas colaborativas.

23 Eco, Umberto - De Bibliotheca. Bostonia. Spring. Boston University, 1993, pp. 39-42.

${ }^{24}$ Figueiredo, António Dias, CAmpos, José - The Serendipity Equations. in Weber, R. and Gresse, C. - Proceedings of the Workshop Program at the Fourth International Conference on Case-Based Reasoning. Washington, DC: Naval Research Laboratory, Navy Center for Applied Research in Artificial Intelligence, 2001.

25 Toms, E.G. - Serendipitous Information Retrieval. Proceedings of the Workshop Information Seeking, Searching and Querying. In Digital Libraries [Em linha]. Zurich: [s.n.], 2000. [Consult. a 20 de Jul. de 2014]. Disponível na WWW em: <URL:http://www.ercim. eu/publication/ws-proceedings/DelNoe01/3_Toms.pdf>; Аввотт, Andrew - The University Library [Em linha]. Chicago: University of Chicago, Setembro de 2008. [Consult. a 20 de Jul. de 2014]. Disponível na WWW em: URL:http://www.lib.uchicago.edu/e/about/abbott-report. html; Digital Public Library Of America - Blog Archive. Planning for Serendipity [Em linha]. [S.L.]: DPLA, 2014. Consult. a 20 de Jul. de 2014]. Disponível na WWW em: <URL:http:// dp.la/info/2014/02/07/planning-for-serendipity/>. 


\subsection{Divisórias versus espaços}

As bibliotecas do passado ofereciam amplos espaços de leitura, onde os leitores partilhavam silêncio e recolhimento. Não havia interação entre os leitores, exceto em iniciativas episódicas de estímulo à leitura, realizadas em locais periféricos, e o espaço aberto e silencioso predominava como característica definidora da biblioteca genuína. Hoje, pelo contrário, várias bibliotecas inovadoras estão a reinventar-se reinventando a utilização dos seus espaços ${ }^{26}$ : recantos tranquilos, espaços de trabalho coletivo, estúdios digitais, espaços de encontro regular com professores e peritos, espaços para a frequência partilhada de MOOCs, centros de negócios, são exemplos de utilizações dos espaços que começam a tornar-se populares e que têm contribuído para fazer afluir entusiasticamente às bibliotecas públicos que tendiam a afastar-se delas.

\subsection{Comunidade versus singularidade}

Para além do atendimento individual que caraterizava as bibliotecas do passado, surge agora a necessidade de apoiar grupos e de contribuir para a criação de comunidade - local, nacional e global - abrindo a biblioteca do indivíduo para a comunidade e o mundo. Para um número crescente de leitores, num número crescente de universidades, a biblioteca é hoje um precioso auxiliar da integração do estudante e do estudioso no grande mundo da pesquisa - um mundo que deixou de se centrar no acesso solitário a recursos bibliográficos para se expressar na pertença a redes dinâmicas de recursos humanos e bibliográficos e de relacionamentos entre uns e outros. Como já se tornava claro há mais de duas décadas, grande parte da informação mais preciosa e atualizada deixou de residir em bases de dados para se encontrar, acima de tudo, na mente coletiva

26 Mullaney, T. - Libraries reinvent themselves for the 21 st century. Chicago Tribune [Em linha]. 2013. [Consult. a 20 de Jul. de 2014]. Disponível na WWW em: <URL:http://articles.chicagotribune.com/2013-12-12/features/chi-library-future-20131212_ 1_library-design-library-leaders-printers-row-journal>. 
dos utilizadores da rede 27 . Estes, pelas suas práticas comunitárias, pela sua atividade como curadores, pelos conselhos que dão, pelos debates que proporcionam, representam hoje inestimáveis recursos para os estudiosos do século XXI. Se a biblioteca interiorizar esse desafio, deixará de ser apenas uma porta de acesso a conteúdos. Passará a ser também uma porta de acesso a pessoas: um espaço de comunicação com peritos e de convivência com pares - que, por sua vez, proporcionarão oportunidades múltiplas e contextualmente enriquecidas de acesso a novos conteúdos e novas pessoas.

\subsection{Bibliotecário versus biblioteca}

À medida que as bibliotecas foram perdendo, para a Internet, a sua importância como repositórios universais de conteúdos, e os leitores e estudiosos emigraram para o novo espaço, o potencial conquistado tornou-se imenso. Aceder a informação simples passou a ser um processo instantâneo e intuitivo, quase dando ideia de que os motores de pesquisa adivinham o que se pretende encontrar. Em contrapartida, a imensidão das possibilidades que se abriram e o ritmo acelerado a que prossegue a sua evolução transformaram a atividade de produção científica com auxílio da Internet em algo que ninguém domina em absoluto ${ }^{28}$. Daí resulta que o bibliotecário dos nossos dias, entendido como perito na mediação do acesso à informação, se esteja a tornar mais importante para os leitores e estudiosos do que o próprio espaço da biblioteca ${ }^{29}$. Como não fará sentido divorciar o bibliotecário da biblioteca, haverá agora que

27 Figueiredo, António Dias - Strategies for a Network to Support Community Action on the Use of Technologies. [Em linha] [Consult. a 20 de Jul. de 2014]. Disponível na WWW em: <URL:http://adfig.com/adfig/docs/1990_stratnet.pdf>.

28 FerY, T. (n.d.) The Future of Libraries. DaVinci Institute [Em linha]. [Consult. a 20 de Jul. de 2014]. Disponível na WWW em: <URL:http://www.davinciinstitute.com/papers/ the-future-of-libraries/>.

29 Godin, Seth - The future of the library. Seth's Blog [Em linha]. 2011. [Consult. a 20 de Jul. de 2014]. Disponível na WWW em: <URL:http://sethgodin.typepad.com/seths_ blog/2011/05/the-future-of-the-library.html>. 
encontrar as formas mais harmoniosas de assegurar que um e outro se completam e constroem mutuamente.

\subsection{O que é um bibliotecário?}

Tendo em conta o ponto anterior, justifica-se realçar aqui algumas das funções que poderão ajustar-se ao papel de um bibliotecário de nova geração. Por um lado, poderá ser um conselheiro sobre procedimentos, qualidade, rigor, relevância e ética da informação. Poderá atuar, também, como curador de informação e recursos humanos - locais, nacionais e internacionais. Poderá desempenhar o papel de pedagogo, que aconselha os seus utentes e contribui para que construam a autonomia e iniciativa de que necessitam para levarem a bom termo as suas pesquisas. Poderá ser um mediador de relacionamentos - locais, nacionais e internacionais. Poderá ser um animador de atividades e iniciativas que assentem no recurso a informação. Finalmente, nesta lista incompleta de funções mais relevantes, poderá ser um consultor de processos organizacionais inovadores, como o lançamento de projetos ou a criação de empresas ${ }^{30}$.

\section{A Biblioteca na Estratégia da Universidade}

Chegados a este ponto, cabe discutir como é que as três áreas identificadas como problemáticas no início deste texto - universidade, construção dos saberes e bibliotecas - poderão conjugar-se na caracterização da biblioteca universitária do futuro.

Antes de mais, a biblioteca deveria ser entendida como uma das principais unidades estratégicas da universidade, que, por sua vez, clarificaria o papel que pretende que ela ocupe ao serviço da sua visão estratégica. Essa clarificação teria em conta, entre outros aspetos: os serviços a prestar aos utentes internos e externos, a forma de contribuir para diferenciar e

30 Godin, Seth - The future of the library. 
afirmar a imagem da universidade e o papel a desempenhar na ligação à comunidade e à realidade produtiva. Interessaria que a universidade clarificasse também a contribuição que a biblioteca pode dar para o reforço das suas políticas de globalização. Idealmente, as lideranças da biblioteca articular-se-iam com as lideranças da universidade no sentido de dar sustentabilidade à visão estratégica partilhada. Seria ideal que essa partilha decorresse num espírito que facilitasse a interrogação crítica dos modelos e práticas e o lançamento exploratório e mutuamente apoiado de inovações disruptivas.

No que se refere aos dilemas da construção dos saberes, importaria que a biblioteca pudesse equacionar o papel a assumir num mundo onde a produção do conhecimento tende a privilegiar cada vez mais o modo 2 . Nesse papel, justificava-se que englobasse nas suas funções a de curadora bidirecional na troca de produção científica e cultural entre universidade e mundo, nos dois sentidos, e a de mediadora bidirecional, dando a conhecer os peritos internos no exterior e os peritos externos no interior. A biblioteca teria também um papel chave na formação e apoio aos seus utentes nos meandros da publicação científica de nova geração. Cobriria assim, não só as novas estratégias e práticas de pesquisa, mas também a grande variedade de métricas hoje em desenvolvimento, que dificilmente podem ser acompanhadas por não especialistas. Em boa verdade, a biblioteca seria a unidade mais privilegiada da universidade para assumir o cultivo aprofundado desta área, incluindo ao nível da investigação.

Os restantes desafios próprios de uma biblioteca do século XXI políticas de aquisição, novas formas de pesquisa, apoio à descoberta acidental, reforço dos contextos, dinamização dos espaços e criação de comunidade - seriam outros tantos fatores a ter em conta na dinâmica de permanente interação entre biblioteca, universidade e produção de conhecimento.

\section{Conclusão}

Há quinhentos anos, as universidades construíam a sua missão em torno dos saberes dos clássicos, que estudavam e aprofundavam no silêncio das 
suas bibliotecas. Os livros eram, então, bens preciosos, protegidos por cadeias que os acorrentavam às mesas, numa ligação que podemos ler hoje como simbolizando a solidez da união entre universidade e biblioteca. Quinhentos anos depois, os livros desmaterializaram-se e os saberes passaram a construir-se dinamicamente, já não só nas universidades, mas também nas redes que as ligam a múltiplas parcerias. No entanto, o valor da união entre universidade e biblioteca mantem-se e tem todas as razões para se renovar. Mais do que uma das suas faculdades ou escolas, uma universidade necessita hoje, como há quinhentos anos, de uma biblioteca que, alinhando-se organicamente com a sua estratégia e a sua missão, a ajude a reinventar-se para os magnos desafios que a confrontam.

\section{Referências bibliográficas}

Аввотт, Andrew - The University Library [Em linha]. Chicago: University of Chicago, Setembro de 2008. [Consult. a 20 de Jul. de 2014]. Disponível na WWW em: <URL:http://www.lib.uchicago.edu/e/about/abbott-report.html>.

BOAI - Budapest Open Access Initiative. [Em linha]. [S.1.]: BOAI, 2002. [Consult. a 20 de Jul. de 2014]. Disponível na WWW em: <URL:http://www.budapestopenaccessinitiative.org/>.

BoAI - A Iniciativa de Acesso Aberto de Budapeste, 10 Anos Depois [Em linha].

[S.L.]: BOAI, 2012 [Consult. a 20 de Jul. de 2014]. Disponível na WWW em: <URL:http://www.budapestopenaccessinitiative.org/boai-10-translations/ portuguese $>$.

CRUZ, Guilherme Braga da - Origem e Evolução da Universidade. In Obras Esparsas, vol. IV, 2. ${ }^{a}$ parte, Coimbra: Universidade, 1985, pp. 189-262.

Christensen, Clayton M. - The Innovator's Dilemma: When New Technologies Cause Great Firms to Fail. Boston, Mass: Harvard Business School Press, 1997. Christensen, Clayton M. - The Innovative University: Changing the DNA of Higher Education from the Inside Out. San Francisco: Jossey-Bass, 2011.

DERridA, Jacques - Of Grammatology. Baltimore: The Johns Hopkins University Press, 1997. 
Digital Public Library of America - Blog Archive. Planning for Serendipity [Em linha]. [S.L.]: DPLA, 2014. Consult. a 20 de Jul. de 2014]. Disponível na WWW em: <URL:http://dp.la/info/2014/02/07/planning-for-serendipity/>.

Eco, Umberto - De Bibliotheca. Bostonia, Spring: Boston University, 1993, pp. 39-42. Economist - Creative Destruction. The Economist [Em linha]. 8 Junho 2014. [Consult. a a 20 de Jul. de 2014]. Disponível na WWW em: <URL:http://www. economist.com/news/leaders/21605906-cost-crisis-changing-labour-marketsand-new-technology-will-turn-old-institution-its $>$.

Figueiredo, António Dias - Strategies for a Network to Support Community Action on the Use of Technologies. In Education and Training [Em linha]. Brussels: Task Force Human Resources, Education, Training and Youth, 1990. [Consult. a 20 de Jul. de 2014]. Disponível na WWW em: <URL:http://adfig.com/adfig/ docs/1990_stratnet.pdf>.

FigueIredo, António Dias - Balanço Final do Encontro, Nova Universidade, Nova Informação: Bibliotecas em Rede [Em linha]. Lisboa: Laboratório Nacional de Engenharia Civil, 1995. [Consult. a 20 de Jul. de 2014]. Disponível na WWW em: <URL:http://eden.dei.uc.pt/ adf/bibrede.htm>.

FigueIREDo, António Dias - Reinventar Portugal: Universidade. Diário Económico. Lisboa: DE, 1996. 12 Julho 1996.

Figueiredo, António Dias, Campos, José - The Serendipity Equations. in Weber, R. and GRESSE, C. - Proceedings of the Workshop Program at the Fourth International Conference on Case-Based Reasoning. Washington, DC: Naval Research Laboratory, Navy Center for Applied Research in Artificial Intelligence, 2001. Figueiredo, António Dias - A Língua Portuguesa e o Desafio das Novas Tecnologias: Iliteracias e Contextos. In A Língua Portuguesa: Presente e Futuro. Lisboa: Fundação Calouste Gulbenkian, 2004.

FigueIREdo, António Dias - Formar para as Humanidades nas Sociedades Contextuais, in SILvA, A. S. [et al.] (eds.) - Novos Horizontes para as Humanidades. Braga: Universidade Católica Portuguesa, 2006, pp. 25-45.

FERY, T. - The Future of Libraries. DaVinci Institute [Em linha]. [Consult. a 20 de Jul. de 2014]. Disponível na WWW em: <URL:http://www.davinciinstitute.com/ papers/the-future-of-libraries/>.

GibBons, Michael [et al.] - The New Production of Knowledge. London: SAGE Publications, 1994. 
Ginsberg, Benjamin - The Fall of the Faculty: The Rise of the All-Administrative University and Why It Matters. New York: Oxford University Press, 2011.

Godin, Seth - The future of the library. Seth's Blog [Em linha]. 2011. [Consult. a 20 de Jul. de 2014]. Disponível na WWW em: URL:http://sethgodin.typepad. com/seths_blog/2011/05/the-future-of-the-library.html.

Hamilton, Buffy J. - Are Librarians, Not Seth Godin, The Ones Missing the Point on Libraries? The Unquiet Librarian [Em linha]. 2011. [Consult. a 20 de Jul. de 2014]. Disponível na WWW em: <URL:http://theunquietlibrarian.wordpress.com/2011/05/16/ are-librarians-not-seth-godin-the-ones-missing-the-point-on-libraries/>.

HAMmer, Michael, CHAMPY - Reengineering the Corporation: A Manifesto for Business Revolution. New York: Harper Collins, 1993.

King, P., Thuna, M. - Altmetrics in Context. Ottawa, Ontario: Canadian Association of Research Libraries, 2013.

Mullaney, T. - Libraries reinvent themselves for the 21st century. Chicago Tribune [Em linha]. 2013. [Consult. a 20 de Jul. de 2014]. Disponível na WWW em: <URL:http://articles.chicagotribune.com/2013-12-12/features/ chi-library-future-20131212_1_library-design-library-leaders-printers-rowjournal>.

ROARMAP - ROARMAP: Registry of Open Access Repositories Mandatory Archiving Policies [Em linha]. [Consult. a 20 de Jul. de 2014]. Disponível na WWW em: <URL:http://roarmap.eprints.org/>.

Shieber, S, Suber, P. - Good Practices For University Open-Access Policies [Em linha]. Harvard: Harvard University, 2013 [Consult. a 20 de Jul. de 2014]. Disponível na WWW em: <URL:http://cyber.law.harvard.edu/hoap/sites/hoap/ images/Bestpracticesguide-2013.pdf $>$.

Toms, E.G. - Serendipitous Information Retrieval. Proceedings of the Workshop Information Seeking, Searching and Querying. In Digital Libraries [Em linha]. Zurich: [s.n.], 2000. [Consult. a 20 de Jul. de 2014]. Disponível na WWW em: <URL:http://www.ercim.eu/publication/ws-proceedings/DelNoe01/3_Toms.pdf>. 
José Augusto Cardoso Bernardes é Professor da Faculdade de Letras da Universidade de Coimbra e Diretor da Biblioteca Geral da Universidade

Ana Maria Eva Miguéis é coordenadora do Serviço Integrado das Bibliotecas da Universidade de Coimbra

Carla Ferreira é bibliotecária nos Serviços de Biblioteca e Documentação da Faculdade de Letras da Universidade de Coimbra. 


\section{Série Documentos}

Imprensa da Universidade de Coimbra

Coimbra University Press

2015

C •

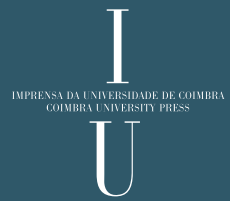

